\title{
Social Interaction Promotes Nicotine Self-Administration with Olfactogustatory Cues in Adolescent Rats
}

\author{
Hao Chen",', Burt M Sharp', Shannon G Matta' and Qingling Wu' \\ 'Department of Pharmacology, University of Tennessee Health Science Center, Memphis, TN, USA
}

\begin{abstract}
Cigarette smoking is a social behavior. Smoking is also accompanied by distinctive gustatory and olfactory stimulation. However, none of these factors affecting nicotine intake are modeled in existing preclinical studies. We report a novel model of adolescent nicotine selfadministration (SA) in rats where licking on drinking spouts was used as the operant behavior to activate the concurrent delivery of nicotine (i.v.) and an appetitive olfactogustatory (OG) cue, and social interaction was required for stable SA. The operant chamber was divided by a panel that separated the SA rat and another rat serving as the demonstrator, who had free access to the OG cue but did not receive nicotine. Orofacial contacts were permitted by the divider. Conditioned taste aversion prevented solo rats to self-administer nicotine. However, stable nicotine ( $15-30 \mu \mathrm{g} / \mathrm{kg}$, free base) SA was established in the presence of demonstrator rats with free access to the OG cue. Omitting the olfactory component of the cue prevented the acquisition of nicotine SA. Mecamylamine, a nicotinic antagonist, reduced licking behavior. Familiar peers were more effective demonstrators in facilitating the acquisition of nicotine SA than were unfamiliar rats. No sex difference in nicotine intake was found. These data indicate that the contingent OG cue is associated with the aversive property of nicotine that prevents subsequent drug intake. Social information encoded in olfaction not only permits the establishment of stable nicotine SA but also enhances nicotine intake. These findings implicate adolescent social interactions in promoting smoking behavior by surmounting the aversive property of nicotine.

Neuropsychopharmacology (20 I I) 36, 2629-2638; doi: I 0.1038/npp.20 I I. I49; published online 27 July 20 I I
\end{abstract}

Keywords: nicotine; aversion; social interaction; gustation; olfaction; adolescence

\section{INTRODUCTION}

Tobacco use is the single most preventable cause of morbidity and mortality in the United States (CDC, 2010). Among the ingredients of tobacco, nicotine is the principal psychoactive agent (Le Foll and Goldberg, 2006, 2009). Nicotine is unique among the many addictive substances in that, despite the high rate of relapse $(\sim 80 \%)$ (Hajek et al, 2009), its primary reinforcing effect is weak (Stolerman and Jarvis, 1995). For example, smoking produces minimal euphoric sensation (Walker et al, 2001). Other subjective effects of nicotine, such as clear-headedness, feelings of relief, fatigue recovery, or hyperactivity, are all mild (Kono et al, 2001). Sensory cues associated with nicotine delivery have a critical role in nicotine addiction (Palmatier et al, 2007). For example, operant lever presses were synergistically increased after combining nicotine with an audiovisual stimulus (Donny et al, 2003). Over 400 flavor additives are

*Correspondence: Dr H Chen, Department of Pharmacology, University of Tennessee Health Science Center, 874 Union Avenue, Memphis, TN 38163, USA, Tel: + | 901448 3720, Fax: + I 901448 7206,

E-mail: hchen@uthsc.edu

Received I6 March 20 I ; revised 3I May 20 I I; accepted 28 June 20 I I used in various tobacco products (Baker et al, 2004). These olfactogustatory (OG) cues associated with nicotine delivery enhance the addictiveness of nicotine. For example, blocking the OG cues reduced the hedonic rating of smoking, as well as puff self-administration (SA) (Perkins et al, 2001), while smokers preferring menthol-flavored cigarettes are nearly twice as likely to relapse as are nonmenthol smokers (Pletcher et al, 2006).

In addition to its weak reinforcing effect, the addictive liability of nicotine is even more perplexing when one considers the fact that most people experience negative subjective effects during their initial exposure of tobacco, such as coughing, dizziness, and nausea (Chen et al, 2003; DiFranza et al, 2004). The aversive effect of nicotine is also evident from animal studies. For example, rats received nicotine injections after consuming flavored liquid reliably avoided that flavor in subsequent tests (Korkosz et al, 2006; Laviolette et al, 2002; Rinker et al, 2008; Shram et al, 2006, Wilmouth and Spear, 2004) (ie, conditioned taste aversion, CTA). Despite the aversive effects, many people continue to smoke and become addicted. The majority $(\sim 80 \%)$ of smokers initiated their consumption of tobacco products in social settings (Greenlund et al, 1997). Peer smoking is one of the strongest predictors of smoking 
initiation (Greenlund et al, 1997). A study following $>700$ twins for 16 years found that smoking behavior of friends, rather than genetics, explained the greater concordance for smoking among adult monozygotic pairs than among dizygotic pairs. Most interestingly, social support (encourage $v s$ discourage) during the first puff also discriminated those who became smokers and those who did not (Hofstetter et al, 2007). Although these findings demonstrated the critical roles of social interaction on human smoking behavior, the majority of preclinical research of smoking has precluded the study of social interaction by using isolated animals.

We report an animal model of nicotine SA in social settings. In this model, i.v. nicotine was delivered with a contingent OG cue. Social transmission of the OG cue from a demonstrator rat permitted the acquisition of nicotine SA. This model provides a unique opportunity to study interactions between nicotine, OG stimulation, and social behavior.

\section{MATERIALS AND METHODS}

\section{Drugs}

Nicotine hydrogen tartrate was purchased from Sigma (St Louis, MO). Nicotine dosages $(\mathrm{pH}=7.2$; calculated as free base), freshly prepared in saline for each cohort of animals, were calculated to deliver $15-60 \mu \mathrm{g} / \mathrm{kg}$ body weight in a $50 \mu \mathrm{l}$ volume. Heparin and Methohexital were purchased from Buttler Schein Animal Health (Dublin, OH).

\section{Animals \\ Adolescent Sprague-Dawley rats (postnatal days, (PN) 29-31) (Harlan Laboratories, Madison, WI) were given 7 days to acclimation to a reversed $12: 12 \mathrm{~h}$ light-dark cycle (lights off at 0930 hours). All procedures were conducted in accordance with the NIH Guidelines Concerning the Care and Use of Laboratory Animals and were approved by the Animal Care and Use Committee of the University of Tennessee.}

\section{Nicotine SA}

Jugular catheters constructed from PE-60 and silastic tubing were implanted in adolescent Sprague-Dawley rats between PN 36 and 38 as previously described (Chen et al, 2007). Rats received 3 days of post surgery recovery. All SA sessions were conducted in the dark-phase of the light cycle and lasted $3 \mathrm{~h}$. Standard rat chow and water were provided ad libitum throughout the experiments, but neither was available during the SA sessions. All rats were group housed with 2-4 peers receiving the same treatment to avoid social isolation induced stress.

Two drinking spouts, each connected to one lickometer controller, were fitted on the same wall of the operant chambers (Med Associates, St Albans, VT). A small current is past between the wire mesh floor and the drinking spout on licking, allowing the number and timing of licks to be recorded. A white cue light and a tone generator were located on the same wall as the drinking spouts. SA was conducted using a fixed ratio 10 and 20-s time-out schedule. Thus, 10 licks on the active spout triggered the concurrent delivery of $60 \mu \mathrm{l} \mathrm{OG}$ cue to the spout and $50 \mu \mathrm{l}$ of nicotine (or saline) through the jugular catheter. The OG cue was $0.4 \%$ saccharin solution containing $0.5 \%$ Hershey's unsweetened cocoa (or $0.1 \%$ unsweetened grape Kool-Aid). A mixture of glucose $(3 \%)$ and saccharin $(0.125 \%)$ (Smith et al, 1976) was also tested in one experiment. The cue light and tone were also turned on during the infusion. Licking on the inactive spout had no programmed consequence. The patency of the jugular catheters was tested periodically using Methohexital $(0.2 \mathrm{ml}, 10 \mathrm{mg} / \mathrm{ml})$.

Progressive ratio testing was conducted on day 11 of SA in one experiment. The number of licks to obtain subsequent infusion was determined using the exponential formula ( $5 \exp (0.2 \times$ injection number $)-5)$, such that the required responses per injection were as follows: $3,6,10,15$, $20,25,32,40,50,62,77,95,118,145,179,219,268,328,402$, 492 , and 603 . Break points were defined by $>20 \mathrm{~min}$ of inactivity on the active spout (Shram et al, 2008).

One group of adolescent female rats received yoked nicotine injections $(15 \mu \mathrm{g} / \mathrm{kg})$ while self-administering the OG solution using FR10 schedule. Both the number and the timing of nicotine injections were programmed according to data obtained from solo rats self-administering nicotine at $15 \mu \mathrm{g} / \mathrm{kg}$.

\section{Social Interaction During Nicotine SA}

A divider located in the middle of the operant chamber separated two rats located on each side, but allowed orofacial contact. A randomly selected demonstrator rat (always the same sex as the SA rat) had free access to the same OG cue received by the SA rat but did not receive i.v. injections. On average, demonstrator rats consumed $30-40 \mathrm{ml}$ of the OG cue per session. The SA rat had access to dedicated drinking spouts as described.

\section{Effect of Familiarity with Demonstrator Rats on Nicotine SA}

Adolescent Lewis rats were used as demonstrators for Sprague-Dawley nicotine SA rats. The SA rats were housed with either the Lewis demonstrators (familiar) or other Sprague-Dawley rats age-matched to the Lewis rats (thus, unfamiliar with the demonstrators) for 1 week before jugular catheter implantation. In the familiar group, the pairing of nicotine SA rats to the Lewis demonstrators was fixed, while a random Lewis demonstrator rat was selected before each session for the SA rats in the unfamiliar group.

\section{Statistics}

Data were presented as mean \pm SEM. All lick and injection data were analyzed by repeated-measures ANOVA, with spout and day treated as within-subject variables. Post hoc analysis was conducted using the Tukey HSD procedure. In dependent $t$-tests were also applied as noted in the results section. All statistical analyses were conducted using $\mathrm{R}$ statistical package (http://www.r-project.org). 

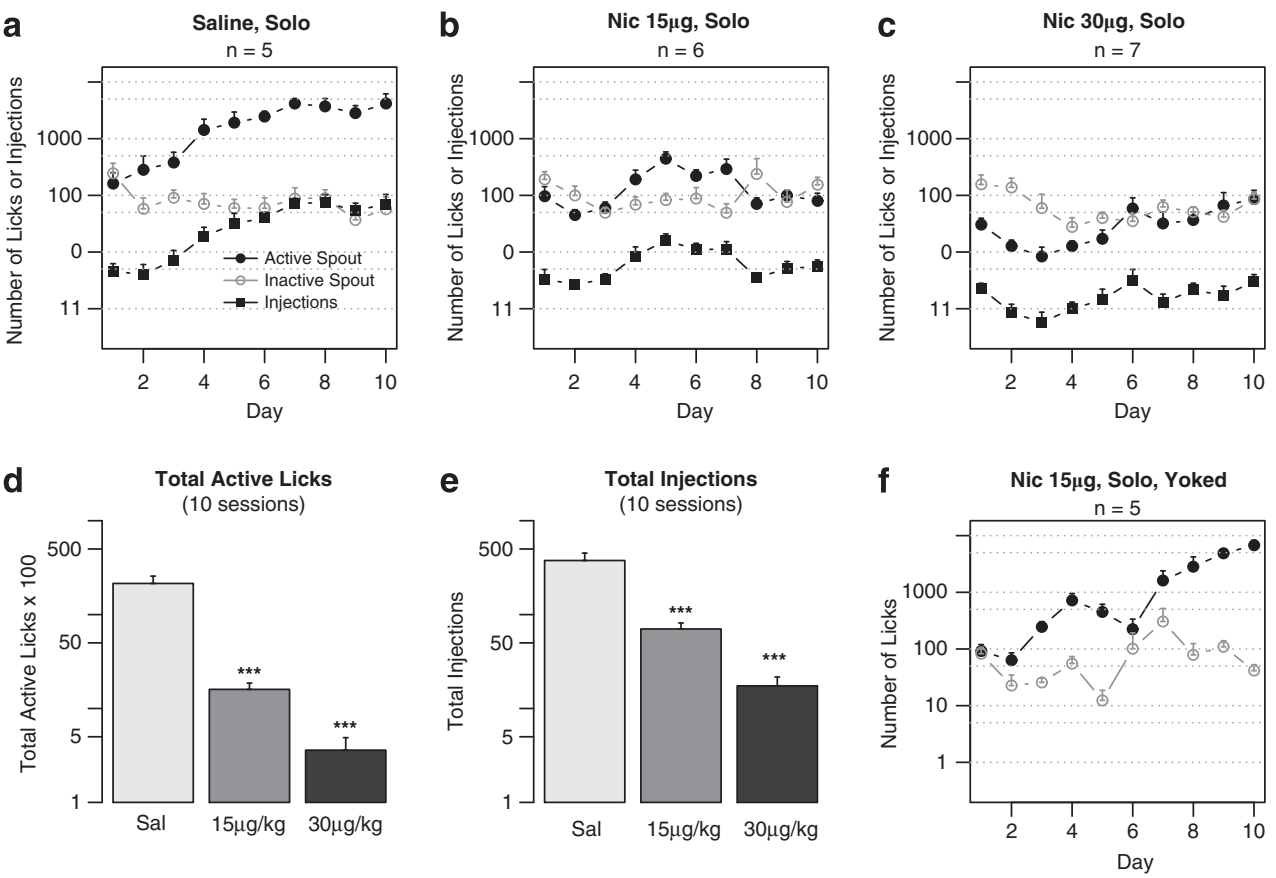

Figure I Adolescent rats did not self-administer i.v. nicotine with contingent OG cues. Adolescent female rats (postnatal days 4I-43) were subjected to daily 3-h nicotine SA sessions. Rats licking on the active spout meeting reinforcement schedule (fixed ratio 10 with 20-s time out) received either I5, $30 \mu \mathrm{g} /$ $\mathrm{kg}$ nicotine, or saline through a jugular catheter and $60 \mu \mathrm{l} \mathrm{OG}$ cue $(20 \mathrm{mM}$ saccharin, $0.5 \%$ unsweetened cocoa) through the active spout. Licking on the inactive spout had no programmed consequences. Rats receiving i.v. saline (a) significantly increased the number of active licks over 10 sessions $(p<0.00 \mathrm{I}$ ). An average of I6I.6 \pm 90.4 active licks was recorded on day I, escalating to 4I62.0 \pm 2016.8 licks on day I0. Licks on the active spout were significantly higher than on the inactive spout $(p<0.00 \mathrm{I})$. Rats receiving $15 \mu \mathrm{g} / \mathrm{kg}(\mathrm{b})$ or $30 \mu \mathrm{g} / \mathrm{kg}$ (c) nicotine injections paired with the $\mathrm{OG}$ cue did not significantly change the number of licks over the 10 sessions $(p>0.05)$. The number of licks was not statistically different between the two spouts for rats receiving $15 \mu \mathrm{g} / \mathrm{kg}(p>0.05)$ but was significantly lower on the active spout for rats receiving $30 \mu \mathrm{g} / \mathrm{kg}(p<0.0 \mathrm{l})$. The total numbers of active licks (d) and injections (e) over the 10 sessions were significantly lower in i.v. nicotine rats ( $p s<0.00 \mathrm{I}$ ). (f) Rats received yoked nicotine $(\mathrm{I} 5 \mu \mathrm{g} / \mathrm{kg})$ gradually increased the number of active licks $(p<0.00 \mathrm{I})$ and developed preference for the active spout $(p<0.00 \mathrm{I})$, demonstrating that contingent delivery of nicotine and $O \mathrm{G}$ cue is required for the reduction in active licks. Together, these results suggest that adolescent rats do not self-administer nicotine with contingent $O G$ cue, likely because of conditioned taste aversion. ${ }^{* * *} p<0.00$ I compared with rats self-administering i.v. saline.

\section{RESULTS}

\section{Adolescent Rats Did Not Self-Administer i.v. Nicotine with Contingent OG Cues}

Adolescent rats (all females) implanted with jugular catheters were subjected to daily 3 -h nicotine SA sessions starting on PN 41-43 in the absence of a demonstrator rat. Licking on the active spout that met reinforcement schedule (FR10, time out $20 \mathrm{~s}$ ) triggers the concurrent delivery of i.v. nicotine $(15$ or $30 \mu \mathrm{g} / \mathrm{kg})$ or saline and $60 \mu \mathrm{l} 20 \mathrm{mM}$ saccharin solution containing $0.5 \%$ unsweetened cocoa. For rats receiving i.v. saline $(n=5$, Figure 1a), there were significant effect for spout (active vs inactive: $\mathrm{F}_{1,40}=44.0$, $p<0.001$ ) on the number of licks. An average of $161.6 \pm 90.4$ licks was emitted on the active spout on day 1, escalating to $4162.0 \pm 2016.8$ licks on day 10 (effect of day on active licks: $\left.\mathrm{F}_{9,36}=2.8, p<0.05\right)$. The effect of day on the number of inactive licks was not significant $\left(\mathrm{F}_{9,36}=2.1, p>0.05\right)$. Thus, the OG cue was appetitive when paired with i.v. saline injection.

In rats receiving $15 \mu \mathrm{g} / \mathrm{kg}$ nicotine injections $(n=6$, Figure 1b), there was no significant effect of day $\left(\mathrm{F}_{9,45}=1.0, p>0.05\right)$ or spout $\left(\mathrm{F}_{1,50}=2.4, p>0.05\right)$ on the number of licks. Rats receiving $30 \mu \mathrm{g} / \mathrm{kg}$ nicotine injections ( $n=7$, Figure 1c) showed no significant change on the number of licks by day $\left(\mathrm{F}_{9,54}=1.1, p>0.05\right)$. The number of licks were significantly different between the spouts $\left(\mathrm{F}_{1,60}=7.2, p<0.01\right)$, with fewer licks emitted on the active spout during days 1-5. Comparing the number of active licks from the three treatments (i.v. saline, 15 and $30 \mu \mathrm{g} / \mathrm{kg}$ nicotine, Figure 1d) found a significant main effect $\left(\mathrm{F}_{2,15}=27.4, p<0.001\right)$. Post hoc analysis found the number of licks was significantly different between all three treatments $(p<0.001$ for saline $v s$ the two nicotine groups and $p<0.01$ between the nicotine groups). The number of injections was also significantly different between the three treatments $\left(\mathrm{F}_{2,15}=26.4, p<0.001\right.$ for the main effect, $p<0.001$ for all pairwise comparisons). Another group of rats $(n=5$, Figure $1 \mathrm{f})$ received programmed i.v. nicotine $(15 \mu \mathrm{g} / \mathrm{kg})$ injections while self-administering the OG solution using a FR10 schedule. These yoked rats showed clear preference for saccharine (effect of day: $F_{9,36}=14.0$, $p<0.001$; effect of spout: $\left.F_{1,40}=49.3, p<0.001\right)$. Therefore, contingent pairing of nicotine with OG cue was necessary to reduce active licks. Together, these results showed that adolescence female rats do not self-administer nicotine with contingent OG cue, even when the OG cue was inherently appetitive. This is potentially because the formation of CTA.

To further test whether CTA was the cause for the reduction in licking when nicotine was available, one group of adolescent female rats $(n=6$, Figure 2a) received OG solution using FR10 schedule for 13 days, with nicotine 

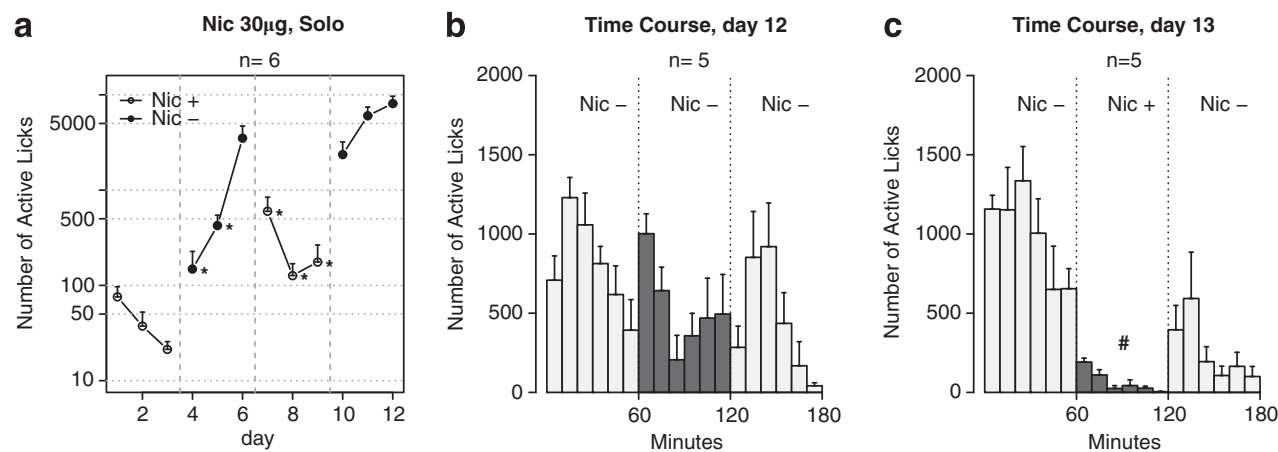

Figure 2 Conditioned taste aversion induced by self-administered nicotine. Adolescent female rats were subjected to 13 daily 3-h SA sessions with the OG cue. Nicotine $(30 \mu \mathrm{g} / \mathrm{kg}$ ) was delivered on days I-3, 7-9 for the entire session and on day I 3 for I h. (a) The number of active licks on day 4 was lower $(p<0.05)$ than those emitted by rats received i.v. saline ( $c f$. Figure Ia), demonstrating CTA. More licks emitted on day 6 after additional extinction training. Licking was significantly reduced on day 7 when nicotine was available, suggesting the aversive effect of nicotine potentially was acute. After additional extinction trainings, rats licked throughout the 3-h sessions on day 12, when nicotine was not delivered (b). However, when nicotine was made available during the second hour of next session, licking behavior was immediately reduced (c). Withholding nicotine delivery again restored licking. When comparing day 12 vs day 13, the number of licks were different for the second hour $(p<0.05)$ but not for the first and third hour. Together, these data suggested that the aversive effect of self-administered nicotine was detected acutely by rats and formed CTA when paired with OG cue. *p $<0.05$ compared with day 6 . ${ }^{\#} p<0.0$ I compared with the second hour on day 12 .

$(30 \mu \mathrm{g} / \mathrm{kg})$ available on days $1-3$ and 7-9. No injection was given on days $4-6$ and $10-12$. Nicotine was available for $1 \mathrm{~h}$ on day 13 . The number of active licks progressively declined during the first 3 nicotine days (effect of day: $\mathrm{F}_{2,10}=6.3$, $p<0.05$ ) but rapidly increased on days 4-6 (effect of day: $\mathrm{F}_{2,10}=7.3, p<0.05$ ), when nicotine was not available. The number of active licks was significantly lower on day 4 when compared with rats received i.v. saline ( $c f$. Figure 1a, $p<0.05$, independent $t$-test). In addition, the number of active licks on day 6 was significantly higher than those on days 4 and 5 ( $p<0.05$, Tukey HSD post hoc). These data suggested that CTA was acquired on days $1-3$ and was extinguished during days $4-6$. The availability of nicotine on days 7-9 reduced active licks $(p<0.05$, day 6 vs 7 ; $p<0.01$, day $6 v s$ days 8 and 9, Tukey HSD post hoc), confirming the aversive effect of nicotine. The number of active licks emitted on day 6 is not statistically different from those emitted during the second extinction phase (days 10-12, $p>0.05$, Tukey HSD), suggesting extinction was likely complete on day 6 . The large number of active licks on day 10 further suggested that the additional pairings of nicotine with the OG cue on days 7-9 did not strengthen CTA and the reduction in active licks during days 7-9 was likely due to the acute aversive effect of nicotine. This was tested on day 13 by making nicotine available only during the second hour of the 3-h session. Rats licked throughout the 3-h sessions on day 12, when nicotine was not delivered (Figure 2b). On day 13, rats licked similar amount compared with day 12 during the first hour (Figure 2c, $F_{1}=6.2, p>0.05$, repeated-measures ANOVA) but significantly reduced licking once nicotine was delivered (Figure $2 c, F_{1,4}=12.7, p<0.05$. The number of active licks was $19.1 \%$, further reduced to $0.8 \%$ for the first and last $10 \mathrm{~min}$, respectively, when compared with the same time period on day 12). Licking resumed once nicotine delivery was stopped during the last hour $\left(\mathrm{F}_{1,4}=2.44, p>0.05\right.$, compared with day 12$)$. Together, these data suggested that the aversive effect of nicotine was acute but it forms conditioned aversion once its delivery was paired with an OG cue.

\section{Social Interaction Permitted Nicotine SA with OG Cue}

As social interaction is known to modulate preference for novel food (Galef, 1986; Galef et al, 1997), we exposed each SA rat (females) to a demonstrator rat (females) during the SA sessions in which the SA rat had free access to the OG cue. In the presence of the demonstrators, rats receiving saline injection showed strong preference for the active over the inactive spout $\left(n=6\right.$, Figure $\left.3 \mathrm{a}, \mathrm{F}_{1,50}=248.1, p<0.001\right)$. Rats receiving $15 \mu \mathrm{g} / \mathrm{kg}$ nicotine ( $n=6$, Figure $3 \mathrm{~b}$ ) gradually escalated the number of active licks to $1413.2 \pm 172.1$ on the last session (27.6 \pm 7.4 -fold increase compared with the first session; the effect of day on the number of licks: $\mathrm{F}_{9,45}=6.2$, $p<0.001)$. As a result, rats received $28.3 \pm 5.2$ nicotine injections on the last session $(7.1 \pm 2.1$-fold increase compared with the first session; the effect of day on the number of injections: $\left.\mathrm{F}_{9,45}=6.6, p<0.001\right)$. The active spout was strongly preferred over the inactive spout $\left(\mathrm{F}_{1,50}=127.1, p<0.001\right.$. The ratio of active/inactive licks was $351.8 \pm 122.4$ on last session). Rats receiving $30 \mu \mathrm{g} / \mathrm{kg}$ nicotine injection $(n=6$, Figure $3 \mathrm{c})$ also demonstrated strong preference for the active spout $\left(\mathrm{F}_{1,50}=28.0\right.$, $p<0.001$. The ratio of active/inactive licks was $47.1 \pm 19.2)$. An average of $603.0 \pm 139.6$ licks was emitted on the active spout, which resulted in $14.2 \pm 2.8$ nicotine injections on the last day of SA. The effect of day on the number of licks $\left(\mathrm{F}_{9,45}=3.4, p<0.01\right)$ and nicotine injections $\left(\mathrm{F}_{9,45}=4.0, p<0.001\right)$ were also statistically significant. In contrast, rats receiving $60 \mu \mathrm{g} / \mathrm{kg}$ nicotine $(n=5$, Figure $3 \mathrm{~d})$ emitted significantly more licks on the inactive spout than on the active spout $\left(\mathrm{F}_{1,40}=6.8, p<0.05\right)$. The effect of day on the number of licks was not significant $\left(F_{9,36}=0.6\right.$, $p>0.05$ ). An alternative olfactory cue (unsweetened grape Kool-Aid) was also tested to confirm that the acquisition behavior is not specific to the OG cue that included unsweetened cocoa ( $n=5$, Figure 3e). The number of active licks was not statistically significant between OG cue with cocoa and OG cue with Kool-Aid at the same nicotine dose $\left(\mathrm{F}_{1,9}=0.04, p>0.05\right)$; neither was the number of injections different $\left(\mathrm{F}_{1,9}=1.3, p>0.05\right)$. The amount of nicotine 

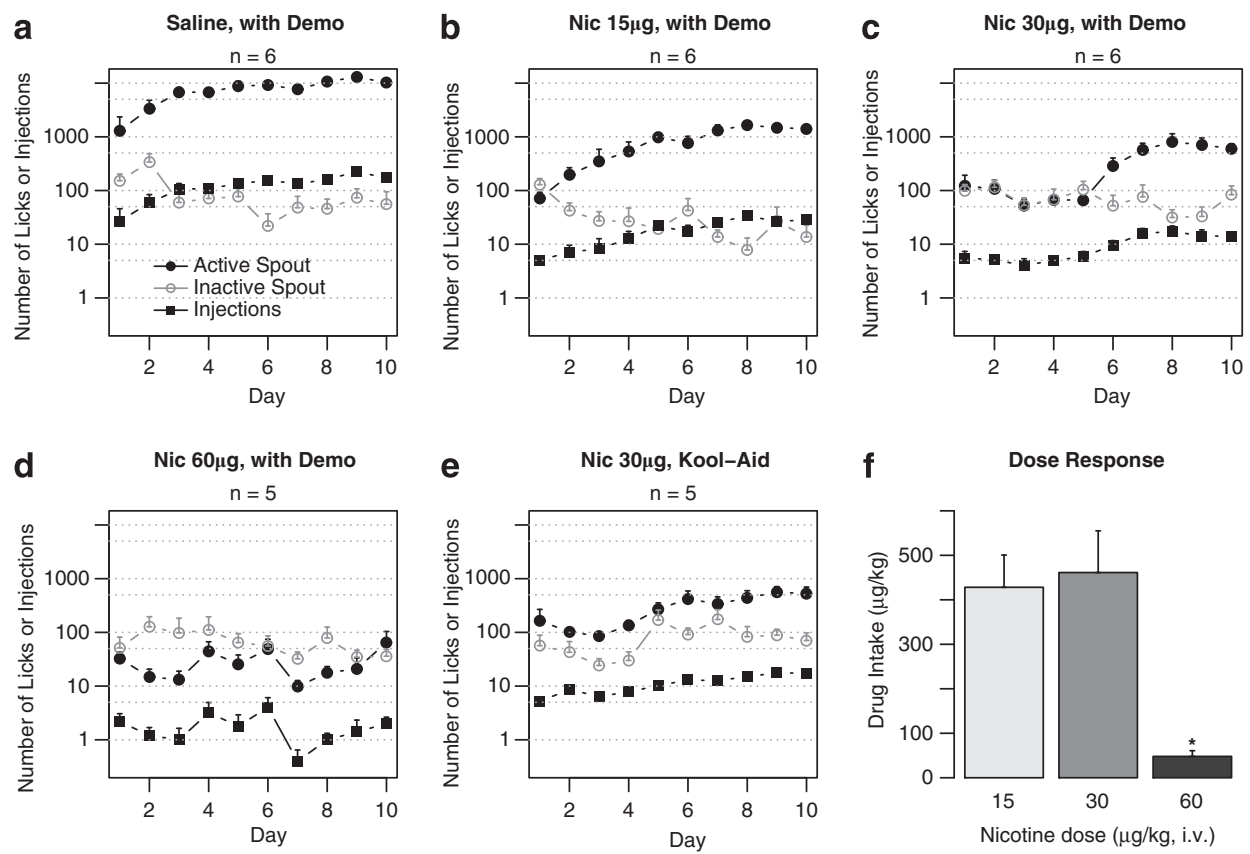

Figure 3 Social interaction promoted nicotine SA with OG cue. The operant chambers were divided by a center panel with holes that separated the rats but allowed physical contact (see Materials and methods section). During SA, each SA rat was exposed to a demonstrator rat, which had free access to the OG cue and received no nicotine injection. Rats self-administering saline (a) injections showed strong preference for the active over the inactive spout $(p<0.00 \mathrm{I}$ ). Rats receiving $15 \mu \mathrm{g} / \mathrm{kg}$ (b) and $30 \mu \mathrm{g} / \mathrm{kg}$ (c) nicotine gradually increased the number of active licks (effect of day: $p<0.00 \mathrm{I}$ and $p<0.0 \mathrm{I}$, respectively) and showed strong preference for the active spout $(p<0.00 \mathrm{I}$ for both doses). In contrast, rats receiving $60 \mu \mathrm{g} / \mathrm{kg}$ nicotine (d) licked more on the inactive spout than on the active spout $(p<0.05)$. The effect of day on the number of licks was not significant $(p>0.05)$. An alternative olfactory cue (unsweetened grape Kool-Aid) (e) was tested to confirm that acquisition behavior was not specific to the cocoa used in the OG cue. At $30 \mu \mathrm{g} / \mathrm{kg}$ nicotine, the number of active licks was not statistically significant between OG cue with cocoa or OG cue with Kool-Aid ( $p>0.05$ ); neither was the number of injections different $(p>0.05)$. The average amount of nicotine self-administered at different doses during the days $7-10$ is shown in ( $f$ ). The was a significant effect of nicotine dose $(p<0.0 \mathrm{I})$. Post hoc Tukey HSD test found that rats took significantly less $(p<0.0 \mathrm{l})$ nicotine at $60 \mu \mathrm{g} / \mathrm{kg}$ than at the two lower doses. * $p<0.0$ I compared with rats self-administering 15 or $30 \mu \mathrm{g} / \mathrm{kg}$ nicotine.

self-administered at different doses during days $7-10$ is shown in Figure 3f. There was a significant effect of nicotine dose $\left(\mathrm{F}_{2,14}=9.2, p<0.01\right)$. Post hoc Tukey HSD test found that rats took significantly less $(p<0.01)$ nicotine at $60 \mu \mathrm{g} / \mathrm{kg}$ than they did at the two lower doses.

\section{Nicotine SA Is Not the Result of Enhanced Appetitiveness of the OG Cue}

As the presence of demonstrators tend to increase the number of active licks in rats receiving i.v. saline $(\mathrm{F}=4.7$, $p=0.059$, cf. Figures $1 \mathrm{a}$ and $3 \mathrm{a}$ ), we tested whether increasing the appetitiveness of the OG cue, by using a mixture of saccharin and glucose (Smith et al, 1976), was sufficient to support nicotine SA. Solo female adolescent rats receiving i.v. saline with contingent oral delivery of saccharin glucose mixture (Smith et al, 1976) emitted a similar amount of licks as rats receiving i.v. saline with saccharine/cocoa in the presence of demonstrators (Figure 4, $\left.\mathrm{F}_{1,9}=0.03, p>0.05\right)$. In a progressive ratio test, the break points achieved by these two treatments were not statistically different (Figure $4 \mathrm{~b}, t$-test, $p>0.05$ ). However, when saccharine glucose mixture was contingently delivered with nicotine without demonstrators, nicotine SA was not established ( $n=6$, Figure 4c. Effect of day on number of licks and injections: $\mathrm{F}_{9,45}=1.5, p>0.05$ and $\mathrm{F}_{9,45}=1.1$, $p>0.05$, respectively; effect of spout on licks: $F_{1,5}=2.6$, $p>0.05)$. Therefore, increasing the appetitiveness of the contingent OG cue alone was not sufficient to support nicotine SA.

\section{Contribution of Nicotine to Operant Licking Behavior}

To confirm that nicotine was reinforcing the operant licking behavior, the OG cue was removed after stable SA had been established. The average number of active licks and injections for the last 3 days of SA with OG cue and subsequence 3 days of SA without the OG cue were shown (Figure 5). Licking was reduced by $98.9 \%$ in saline rats after OG cue removal $\left(n=5\right.$, Figure $\left.5 a, \mathrm{~F}_{1,18}=29.9, p<0.01\right)$. The number of injections was reduced by $97.8 \%$ (Figure $5 \mathrm{~b}$, $\left.\mathrm{F}_{1,18}=28.1, p<0.001\right)$, indicating in rats receiving saline injection, licking behavior is solely driven by the OG solution. In rats that self-administered $30 \mu \mathrm{g} / \mathrm{kg}$ nicotine (and receiving vehicle s.c. injection before each session), the number of active licks was reduced by $46.9 \%$ after the removal of OG cue $\left(n=7\right.$, Figure $\left.5 \mathrm{a}, \mathrm{F}_{1,26}=7.8, p<0.05\right)$. However, the number of injections was reduced by only $8.1 \%$ in the absence of the OG cue (Figure $5 \mathrm{~b}, \mathrm{~F}_{1,26}=0.4$, $p>0.05$ ), indicating licking behavior is driven, in part, by nicotine in these animals. Licking by nicotine SA rats was reduced by $84.4 \%\left(n=5\right.$, Figure $\left.5 \mathrm{a}_{1,18}=14.4, p<0.01\right)$ and the number of injections was reduced by $72.4 \%$ (Figure $5 \mathrm{~b}, \mathrm{~F}_{1,18}=16.7, p<0.001$ ), when mecamylamine, a non-competitive nicotinic receptor antagonist $(1.5 \mathrm{mg} / \mathrm{kg}$, s.c.) was administered $15 \mathrm{~min}$ before each of the SA sessions 

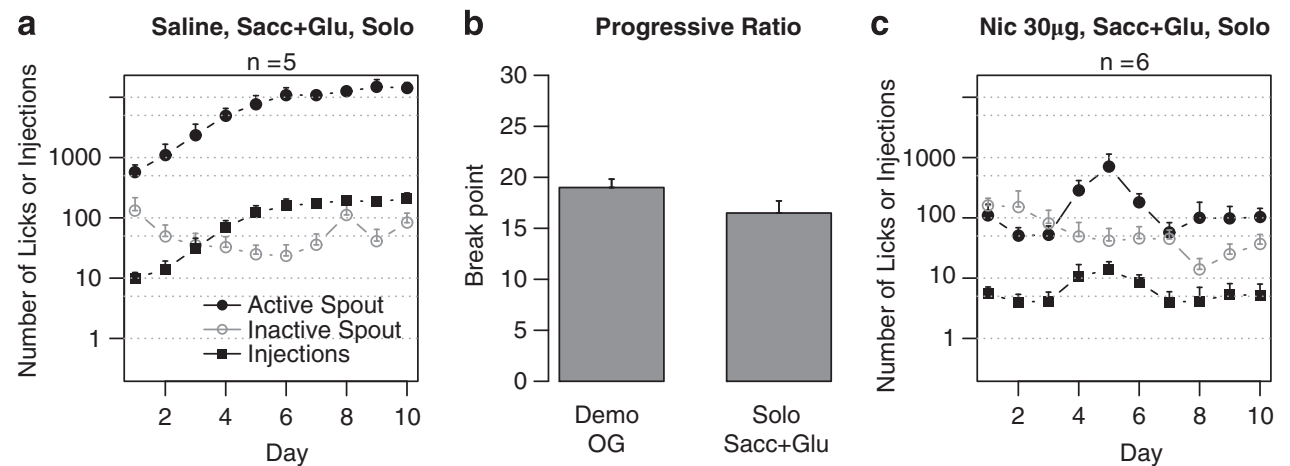

Figure 4 Increasing the appetitiveness of the OG cue was not sufficient to support nicotine SA. Rats are known to have strong preference to saccharine + glucose mixture. The number of active licks emitted by solo rats receiving i.v. saline paired with saccharine + glucose mixture (a) was not statistically different from the number of active licks emitted by rats receiving $O G$ cue with the demonstrators $(p>0.05, c f$. Figure $2 b)$. Progressive ratio test (b) found that the break points achieved by these two treatments were not statistically different $(p>0.05)$. However, when saccharine + glucose mixture was used as the OG cue in the absence of demonstrators (c), stable nicotine intake was not established. The p-value for the effect of day on licks and injections, and the difference between spouts are all $>0.05$.
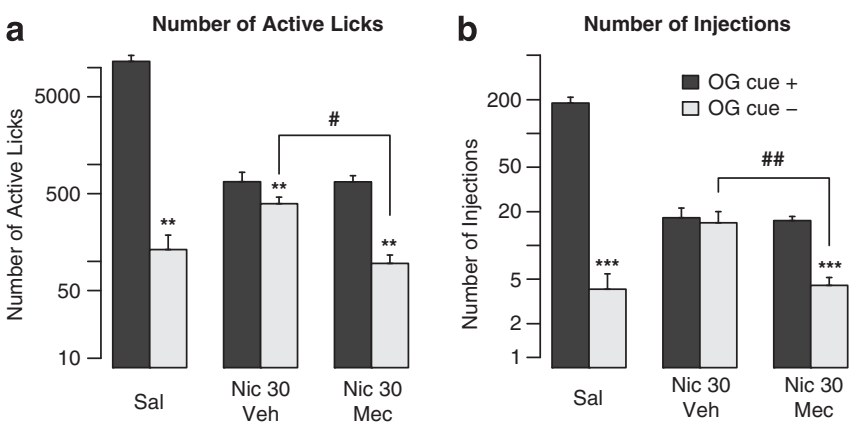

Figure 5 Operant licking behavior was partially reinforced by nicotine. OG cue was removed once stable SA was established. The average number of active licks (a) and injections ( $b$ ) for the 3 days before and after removal of the OG cue was shown. In control rats receiving saline injections, removing the $O G$ cue reduced active licks and injections by $98.9 \%$ and $97.8 \%$, respectively ( $p<0.00$ I for both), indicating licking behavior was entirely driven by the $O C$ due in these rats. For rats selfadministering $30 \mu \mathrm{g} / \mathrm{kg}$ nicotine, the number of active licks was reduced by $46.9 \%(p<0.05)$ after the removal of OG cue, indicating licking behavior was only partially driven by the OG cue in these animals. The role of nicotine in reinforcing licking behavior is further supported by the insignificant reduction $(8.1 \%, p>0.05)$ in nicotine injection in the absence of OG cue. Licking on the active spout however, was significantly reduced (84.4\%, $p<0.0 \mathrm{I})$ when mecamylamine, a non-competitive nicotinic receptor antagonist was administered $(1.5 \mathrm{mg} / \mathrm{kg}, \mathrm{s.c.}$.) $15 \mathrm{~min}$ before each of the OG cue-lacking SA sessions, so was the number of injections significantly reduced $(72.4 \%, p<0.001)$. *** $p<0.01$, ***** $p<0.00$ I compare with days with $O G$ cue. ${ }^{\#} p<0.05 ;{ }^{\#} p<0.01$, compared with vehicle injection before SA.

in which the OG cue was absent, further confirming the role of nicotine in operant licking behavior. Compared with nicotine SA rats receiving vehicle injections, rats receiving mecamylamine injections had significantly fewer active licks $\left(\mathrm{F}_{1,10}=9.8, p<0.05\right)$ and obtained significantly fewer injections $\left(\mathrm{F}_{1,10}=7.5, p<0.01\right)$. Therefore, in the absence of the OG cue, nicotine still reinforced the licking behavior.

\section{Social Information Is Encoded in Olfaction}

To identify the social information that permitted the acquisition of nicotine SA, we removed the olfactory
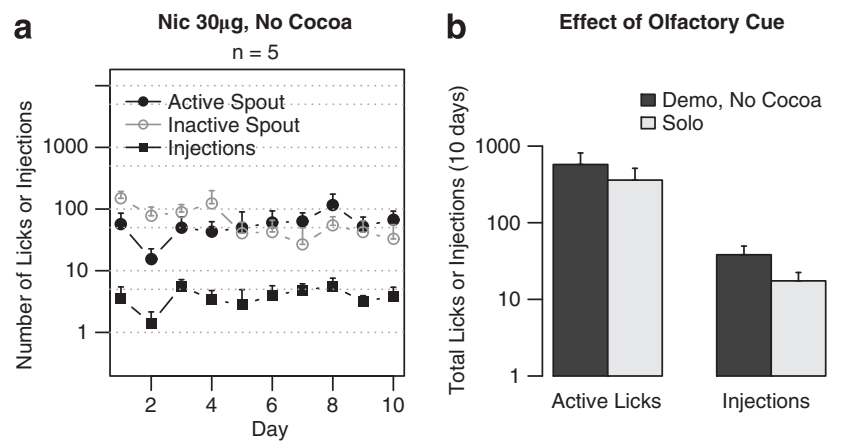

Figure 6 Social information is encoded in olfaction. (a) Unsweetened cocoa, the olfactory component of the OG cue, was removed for both the demonstrator and SA rats. Nicotine SA was not established under this condition. The effects of day on active licks and injections were not significant ( $p>0.05$ for both). The difference between active and inactive licks was not significant either $(p>0.05)$. (b) The numbers of active licks and nicotine injections were not statistically different from those tested in the absence of demonstrators ( $p>0.05$ for both).

component (unsweetened cocoa) from the OG cue of both the demonstrator rats and the SA rats (all females). Nicotine SA was not established under this condition $(n=5$, Figure 6a). The effects of day on active licks and injections were not significant $\left(\mathrm{F}_{9,36}=1.5, p>0.05\right.$, and $\mathrm{F}_{9,36}=1.3$, $p>0.05$, respectively). The difference between active and inactive licks was not significant either $\left(\mathrm{F}_{1,4}=0.4, p>0.05\right)$. In fact, the numbers of active licks were not statistically different from those tested in the absence of demonstrator rats (Figure $6 \mathrm{~b}, \mathrm{~F}_{1,10}=0.8, p>0.05$ ). Thus, olfactory cue present in the demonstrator's breath is likely the source of the social information that modulated nicotine intake.

\section{Social Interaction Is Not Required to Maintain Nicotine SA}

Female adolescent rats self-administered $15 \mu \mathrm{g} / \mathrm{kg}$ nicotine for 10 sessions with demonstrators, followed by five sessions without the demonstrators $(n=7$, Figure 7$)$. The numbers of active licks and nicotine injections were reduced by $24.6 \pm 6.9 \%$ and $25.0 \pm 8.1 \%$, respectively, in the absence of the demonstrators $\left(F_{1,54}=20.5, p<0.001\right.$, 


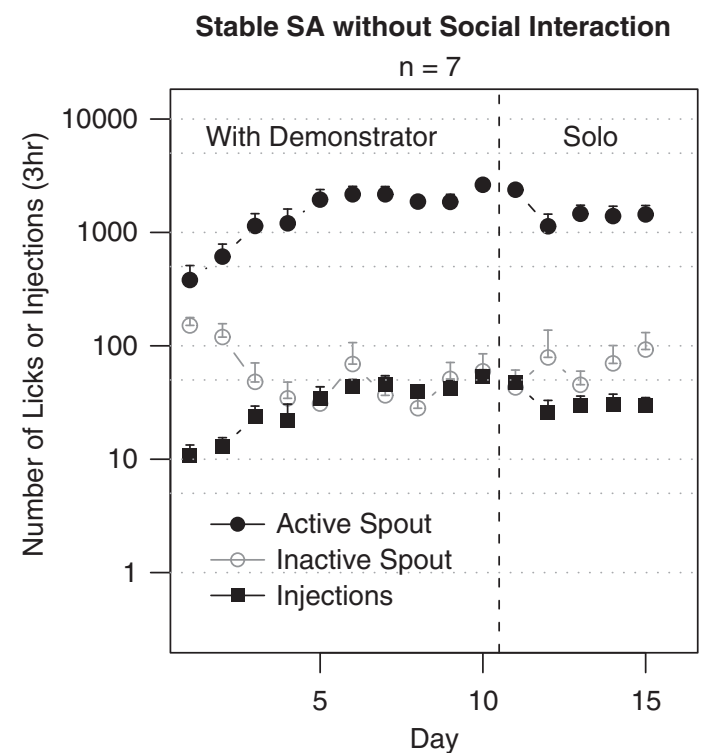

Figure 7 Social interaction was not required to maintain nicotine SA. Rats self-administered $15 \mu \mathrm{g} / \mathrm{kg}$ nicotine for 10 days with demonstrator rats. The demonstrators were absent for the five subsequent sessions. Rats maintained nicotine intake in the absence of the demonstrators. Although the numbers of active licks and nicotine injections were reduced by $24.6 \pm 6.9 \%$ and by $25.0 \pm 8.1 \%$, respectively $(p<0.01$ and $p<0.05$, respectively), rats maintained a strong preference to the active spout in that the ratio of active vs inactive licks was $27.6 \pm 44.8$ (active vs inactive: $p<0.001)$.

and $\mathrm{F}_{1,54}=18.4, p<0.001$, respectively). However, rats still licked $1532.2 \pm 207.8$ times on the active spouts without the demonstrators, which was $27.6 \pm 44.8$-fold of those on the inactive spouts (effect of spout: $F_{1,60}=126.0, p<0.001$ ). Therefore, although social interaction was not required to maintain nicotine SA with OG cue, it continued to promote nicotine intake.

\section{Familiar Peers Were More Effective in Facilitating Nicotine SA}

Female Lewis rats were used as demonstrators for SpragueDawley SA rats to enlarge the difference in familiarity between the two treatment groups. Adolescent female Sprague-Dawley SA rats were housed with either the Lewis demonstrator rats (familiar group) or age-matched Sprague-Dawley rats (unfamiliar to the Lewis demonstrator rats) for 1 week before jugular surgery. Both groups acquired nicotine SA (Figure 8). The number of active licks and nicotine injections during the last 5 sessions by rats familiar to the demonstrators (previous cage-mates) were $2.6 \pm 0.3$ - and $1.7 \pm 0.1$-fold greater than those unfamiliar to the demonstrator rats $\left(\mathrm{F}_{1,12}=10.8, p<0.01\right.$ and $\mathrm{F}_{1,12}=3.9$, $p=0.07$ ), respectively. Thus, the capacity of familiar peers in modulating nicotine intake is greater than those of the unfamiliar peers.

\section{Effect of Sex on Acquisition}

Male adolescent rats were subjected to nicotine $(30 \mu \mathrm{g} / \mathrm{kg})$ SA with contingent $O G$ cue in the presence of male demonstrator rats. The number of active licks and nicotine
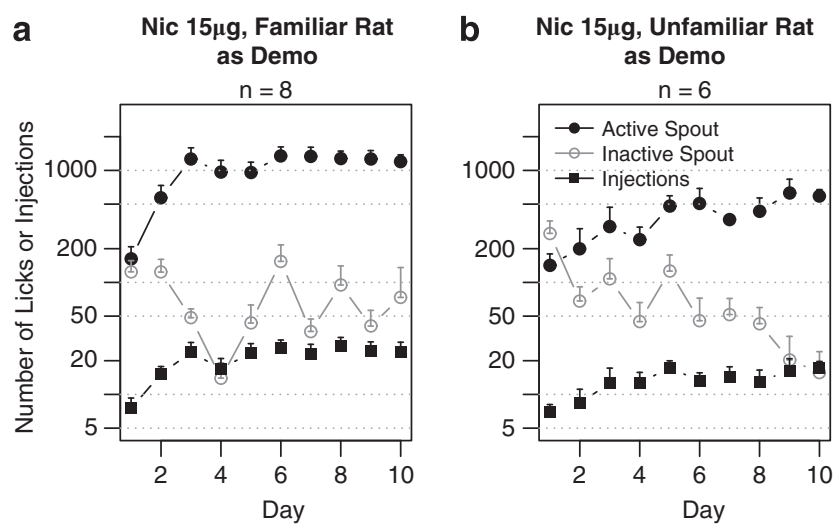

Figure 8 Familiar peer was more effective in promoting nicotine SA. Lewis rats were used as demonstrators. SD rats were housed either with the Lewis demonstrators for I week (a) or with other SD rats (b) before nicotine SA sessions. Both groups acquired nicotine SA (active vs inactive: $p>0.01$ for both). Rats exposed to familiar demonstrators licked $1283.6 \pm 193.3$ times on the active spout during the last 5 days of SA. In contrast, rats exposed to unfamiliar demonstrators licked $504 \pm 86.5$ times during the same time period, reflecting a $2.6 \pm 0.3$-fold difference $(p<0.0 \mathrm{I})$, which resulted in a $1.7 \pm 0.1$-fold difference in nicotine intake $(p=0.07)$.

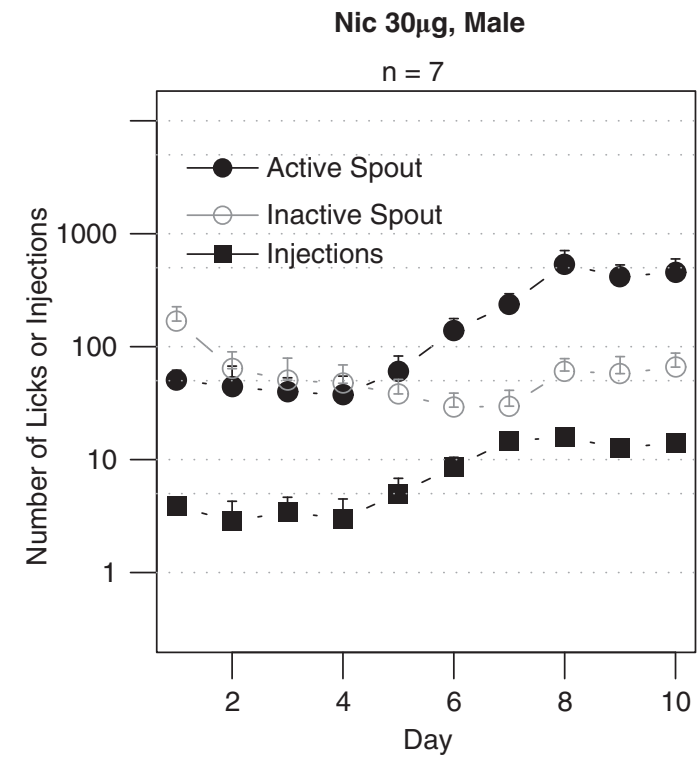

Figure 9 No sex differences on acquisition. Male adolescent rats were subjected to nicotine $(30 \mu \mathrm{g} / \mathrm{kg})$ SA with contingent OG cue with male demonstrators. Both active licks and nicotine injections significantly increased over the 10 daily sessions $(p<0.001$ for both). Active licks were significantly higher than inactive licks $(p<0.00 \mathrm{I})$. When compared with female adolescent rats subjected to the same treatment, neither the number of active licks nor the number of injections was statistically different ( $p>0.05$ for both).

injections significantly increased over the 10 daily sessions $\left(n=7\right.$, Figure $9, \quad \mathrm{~F}_{9,54}=6.5, p<0.001$, and $\mathrm{F}_{9,54}=9.6$, $p<0.001$, respectively). The number of licks was significantly different between the two spouts $\left(F_{1,60}=26.2\right.$, $p<0.001)$. When compared with female adolescent rats subjected to the same treatment, neither the number of active licks $\left(\mathrm{F}_{1,11}=3.1, p>0.05\right)$ nor the number of injections $\left(\mathrm{F}_{1,11}=0.7, p>0.05\right)$ was statistically significant. 


\section{DISCUSSION}

We report an adolescent rat model of i.v. nicotine SA with contingent OG cue, in which social interaction was required for the acquisition, but not the maintenance of nicotine SA. It is generally recognized that drugs of abuse, including nicotine (Garrett and Griffiths, 2001; Harvey et al, 2004), have both rewarding and aversive effects. For example, rats have been shown to avoid saccharin solution if it is provided immediately before SA (Wheeler et al, 2008; Wise et al, 1976). Although continued SA demonstrated the rewarding effects, the avoidance of saccharin intake suggested that aversive effects were induced (for an alternative interpretation, see Grigson, 2008). We found that rats avoided the OG cue when it was paired with nicotine ( 15 or $30 \mu \mathrm{g} / \mathrm{kg}$, Figures $1 \mathrm{~b}$ and $\mathrm{c}$ ), although the $\mathrm{OG}$ cue was appetitive to rats receiving i.v. saline (Figure 1a). A recent study, similar to ours, found that rats pressing a lever to receive contingent i.v. nicotine and an olfactory cue (through implanted oral catheter), failed to self-administer nicotine (Grebenstein and Rowland, 2010). These data are in agreement with reports demonstrating that nicotine induces CTA (Korkosz et al, 2006; Rinker et al, 2008; Wilmouth and Spear, 2004). Indeed, when rats received yoked nicotine, strong preference to the active spout was developed (Figure 1f), suggesting that contingent delivery of nicotine and the OG cue is critical for the reduction in licking. To test if CTA was acquired, one group of rats received $O G$ cue for 13 days but nicotine was withheld on days 4-6 and 10-12 (Figure 2). As expected, active licks increased progressively during days 4-6, reaching levels similar to those receiving saline by day 6 (Figure 1a). Thus, the low amount of active licks on day 4 ( $\sim 4 \%$ of day 6$)$ is likely a result of CTA. Neophobia, a potential alternative explanation, is unlikely because rats received i.v. saline (and should also experience neophobia) emitted $>1000$ active licks on day 4 (Figure 1a). When these rats again received nicotine on days 7-9, the number of licks reduced again. Together with the yoke data, the reduction on day 7 suggested that the aversive effect of nicotine is likely acute. This was confirmed by data showing that in rats received extinction training, strong licking response in the absence of nicotine was immediately reduced once nicotine was delivered, while withholding nicotine delivery again enabled licking (Figures $2 \mathrm{~b}$ and $\mathrm{c}$ ). These results indicating aversive effect as a result of nicotine exposure are consistent with reports in human subjects, in which negative effects (such as tension, jitteriness, and dysphoria) were reported not only on initial exposure (Chen et al, 2003; DiFranza et al, 2004; Shram et al, 2006) but also in experienced smokers after extended tobacco use (Garrett and Griffiths, 2001; Jones et al, 1999; Le Foll and Goldberg, 2009).

Although social environments, ranging from having friends who smoke (Flay et al, 1994) to being exposed to smoking scenes in movies (Charlesworth and Glantz, 2005; Sargent, 2005), have been shown to promote smoking in teenagers, peer interaction in rodents has also been shown to overcome CTA. For example, rats reduced subsequent intake of unfamiliar food if they were injected with illnessinducing agents after their initial exposure. However, exposing rats to a demonstrator who just consumed the same flavored food (Galef, 1986) or fluid (Galef et al, 1997) reversed this aversion. In fact, social transmission of food preference (STFP), that is, favoring an unfamiliar food after interacting with a conspecific immediately after it consumed the same food, is well established (Dindo et al, 2011; Galef et al, 1997; Solomon et al, 2002; Wrenn, 2004). Carbon disulfide, a volatile compound contained in rat breath and detected by dedicated olfactory sensory neurons (Munger et al, 2010), is required for STFP (Galef et al, 1988). We thus modeled social interaction in teenage smokers by including a demonstrator rat in the SA sessions. The demonstrator had free access to the OG cue but did not receive nicotine infusions. A divider with holes separated the demonstrator from the SA rat, but allowed orofacial interaction. In the presence of the demonstrator, stable nicotine SA was observed at both 15 and $30 \mu \mathrm{g} / \mathrm{kg}$, but not at $60 \mu \mathrm{g} / \mathrm{kg}$ (Figure 3). The failure to establish nicotine SA at the highest dose was likely due to larger aversive effects of nicotine and the limited efficacy of social interaction (Galef and Whiskin, 1998). Once nicotine SA was acquired, social interaction was no longer required to maintain the behavior. However, social interaction still promoted nicotine intake after acquisition, because less nicotine was taken in the absence of the demonstrator (Figure 7).

As the OG cue was appetitive, it could be argued that SA was entirely driven by the OG cue. To test the role of nicotine in the operant licking behavior, we withheld the OG cue after 10 days of SA (Figure 5). Although nicotine SA rats reduced licking on the active spout by $46.9 \%$, the number of injections they received was reduced by only $8.1 \%$. The reduction in active licks reflected the portion of active licks emitted while consuming the OG cue. However, in the absence of the OG cue, rats continued to lick the dry spout to obtain nicotine. Application of mecamylamine, a non-competitive nicotinic acetylcholine receptor antagonist, significantly reduced nicotine intake by $72.4 \%$, demonstrating that the operant licking behavior depends, in part, on nicotine. Although the OG cue makes considerable contribution toward licking behavior, it is possible that with prolonged training, the licking response will be more depend on nicotine rather than the OG cue, as demonstrated in non-human primate studies (Le Foll et al, 2007).

Odors are critical for social interaction in rodents. Removing unsweetened cocoa from the cue abolished nicotine SA (Figure 6a), while unsweetened Kool-Aid was equally effective as cocoa in supporting nicotine SA (Figure 3f). These findings showed that modulating nicotine intake by social interaction requires the social transmission of a nicotine-associated odor from a peer, but that the innate quality of the odor does not have a critical role.

We further tested the hypothesis that different social relations (ie, familiar $v s$ unfamiliar) vary in their capacity to modulate nicotine intake. Figure 8 shows that rats accompanied by familiar peers had greater nicotine intake than those with unfamiliar peers. These results are in agreement with report that partner familiarity regulates voluntary ethanol intake in rats (Maldonado et al, 2008). Together, they indicate that the effect of social interaction on drug intake is not solely determined by a signature odor, such as carbon disulfide (Galef et al, 1988); rather, it also involves the complex process of individual recognition.

We used primarily female adolescent rats in this study. However, male adolescent rats also acquired nicotine SA at 
similar levels as females (Figure 9). Although this did not rule out the possibility that potential sex difference exists at different doses of nicotine and/or OG odor or reinforce schedule other than those studied (Chaudhri et al, 2005), nevertheless, social modulation of nicotine SA is not specific to females.

It is possible that demonstrators enhanced the appetitiveness of the OG cue, overcoming the aversiveness induced by nicotine and permitted nicotine SA. Thus, a sufficiently appetitive OG cue would support the acquisition of nicotine SA without social interaction. We tested this hypothesis by using a saccharin-glucose mixture, which is strongly preferred by rats (Smith et al, 1976). The appetitiveness and motivational effects of the saccharinglucose mixture in the absence of the demonstrators were similar to those of saccharin in the presence of the demonstrators (Figures $3 \mathrm{~b}$ and $4 \mathrm{a}$ ). However, rats failed to acquire nicotine SA when saccharin-glucose mixture was the OG cue in the absence of demonstrators (Figure 4c). Therefore, enhancing the appetitiveness of the OG cue does not appear to be the mechanism by which social interaction modulates nicotine SA. Alternatively, social interaction might support nicotine SA with OG cue by enhancing the rewarding effects of nicotine. A recent study showed that a low dose of nicotine interacted with social reward to enhance conditioned place preference (Thiel et al, 2009). However, in our model, interaction with a demonstrator rat taking the saccharin solution without the odor cue (unsweetened cocoa) was not sufficient to support nicotine SA (Figure 6a). Thus, the enhancement of nicotine reward by social interaction, if present in our model, is not sufficient to support nicotine SA.

Based on forgoing discussion, the most likely mechanism for social interaction to enable nicotine SA in this model is by either blocking or reversing nicotine-induced CTA. The neurochemical or molecular mechanisms underlie this effect are unknown. Oxytocin, a neuropeptide synthesized by magnocellular neurons in hypothalasmus and supraoptic nucleus, has been implicated in numerous social behaviors, including parenting, affiliation, social cognition (Choleris et al, 2009; Insel, 2010; Ross and Young, 2009), and social recognition (Choleris et al, 2009). Oxytocin also regulates dopaminergic neurotransmission in the mesolimbic system (Melis and Argiolas, 2011). Therefore, oxytocin is a potential common molecular target that facilitates nicotine SA in rodents as well as in adolescent smokers.

In summary, we have established an i.v. nicotine SA model in which nicotine was delivered with a contingent OG cue in adolescent rats. Social interaction with a peer, actively consuming the same OG cue, was required to establish nicotine intake. Although social interaction was not required to maintain nicotine intake, it nevertheless promoted greater intake of nicotine once the behavior was established. This rodent model encompassed a comprehensive set of sensory and social cues implicated in human smoking behavior; therefore, it is an ideal tool to dissect the complex interplay between social and environmental factors and sensory stimulation, and the roles they have in determining the affective response to nicotine and the motivation to obtain nicotine. Our current findings support the postulate that adolescent social interactions may promote human smoking behavior by surmounting the aversive properties of nicotine.

\section{ACKNOWLEDGEMENTS}

We thank Dr William Woolverton for his insightful discussions. Funding was provided by NIDA Grant DA026894 (HC).

\section{DISCLOSURE}

The authors declare no conflict of interest.

\section{REFERENCES}

Baker RR, Pereira da Silva JR, Smith G (2004). The effect of tobacco ingredients on smoke chemistry. Part I: flavourings and additives. Food Chem Toxicol 42(Suppl): S3-S37.

CDC (2010). Vital signs: current cigarette smoking among adults aged $>$ or $=18$ years - United States, 2009. MMWR Morb Mortal Wkly Rep 59: 1135-1140.

Charlesworth A, Glantz SA (2005). Smoking in the movies increases adolescent smoking: a review. Pediatrics 116: 1516-1528.

Chaudhri N, Caggiula AR, Donny EC, Booth S, Gharib MA, Craven LA et al (2005). Sex differences in the contribution of nicotine and nonpharmacological stimuli to nicotine self-administration in rats. Psychopharmacology (Berl) 180: 258-266.

Chen H, Matta SG, Sharp BM (2007). Acquisition of nicotine selfadministration in adolescent rats given prolonged access to the drug. Neuropsychopharmacology 32: 700-709.

Chen X, Stacy A, Zheng H, Shan J, Spruijt-Metz D, Unger J et al (2003). Sensations from initial exposure to nicotine predicting adolescent smoking in China: a potential measure of vulnerability to nicotine. Nicotine Tob Res 5: 455-463.

Choleris E, Clipperton-Allen AE, Phan A, Kavaliers M (2009). Neuroendocrinology of social information processing in rats and mice. Front Neuroendocrinol 30: 442-459.

DiFranza JR, Savageau JA, Fletcher K, Ockene JK, Rigotti NA, McNeill AD et al (2004). Recollections and repercussions of the first inhaled cigarette. Addict Behav 29: 261-272.

Dindo M, Stoinski T, Whiten A (2011). Observational learning in orangutan cultural transmission chains. Biol Lett 7: 181-183.

Donny EC, Chaudhri N, Caggiula AR, Evans-Martin FF, Booth S, Gharib MA et al (2003). Operant responding for a visual reinforcer in rats is enhanced by noncontingent nicotine: implications for nicotine self-administration and reinforcement. Psychopharmacology (Berl) 169: 68-76.

Flay BR, Hu FB, Siddiqui O, Day LE, Hedeker D, Petraitis J et al (1994). Differential influence of parental smoking and friends' smoking on adolescent initiation and escalation of smoking. J Health Soc Behav 35: 248-265.

Galef Jr BG (1986). Social interaction modifies learned aversions, sodium appetite, and both palatability and handling-time induced dietary preference in rats (Rattus norvegicus). J Comp Psychol 100: 432-439.

Galef Jr BG, Mason JR, Preti G, Bean NJ (1988). Carbon disulfide: a semiochemical mediating socially-induced diet choice in rats. Physiol Behav 42: 119-124.

Galef Jr BG, Whiskin EE (1998). Limits on social influence on food choices of Norway rats. Anim Behav 56: 1015-1020.

Galef Jr BG, Whiskin EE, Bielavska E (1997). Interaction with demonstrator rats changes observer rats' affective responses to flavors. J Comp Psychol 111: 393-398.

Garrett BE, Griffiths RR (2001). Intravenous nicotine and caffeine: subjective and physiological effects in cocaine abusers. J Pharmacol Exp Ther 296: 486-494.

Grebenstein PE, Rowland NE (2010). Flavor cues and nicotine selfadministration. Soc Neurosci Annu Meet Abstr 305.6. 
Greenlund KJ, Johnson CC, Webber LS, Berenson GS (1997). Cigarette smoking attitudes and first use among third- through sixth-grade students: the Bogalusa Heart Study. Am J Public Health 87: 1345-1348.

Grigson PS (2008). The state of the reward comparison hypothesis: theoretical comment on Huang and Hsiao (2008). Behav Neurosci 122: 1383-1390.

Hajek P, Stead LF, West R, Jarvis M, Lancaster T (2009). Relapse prevention interventions for smoking cessation. Cochrane Database Syst Rev (1) Art. no.: CD003999.

Harvey DM, Yasar S, Heishman SJ, Panlilio LV, Henningfield JE, Goldberg SR (2004). Nicotine serves as an effective reinforcer of intravenous drug-taking behavior in human cigarette smokers. Psychopharmacology (Berl) 175: 134-142.

Hofstetter CR, Hovell MF, Jung KR, Raman R, Irvin V, Ni R (2007). The first puff: forces in smoking initiation among Californians of Korean descent. Nicotine Tob Res 9: 1277-1286.

Insel TR (2010). The challenge of translation in social neuroscience: a review of oxytocin, vasopressin, and affiliative behavior. Neuron 65: 768-779.

Jones HE, Garrett BE, Griffiths RR (1999). Subjective and physiological effects of intravenous nicotine and cocaine in cigarette smoking cocaine abusers. J Pharmacol Exp Ther 288: 188-197.

Kono J, Miyata H, Ushijima S, Yanagita T, Miyasato K, Ikawa G et al (2001). Nicotine, alcohol, methamphetamine, and inhalant dependence: a comparison of clinical features with the use of a new clinical evaluation form. Alcohol 24: 99-106.

Korkosz A, Scinska A, Taracha E, Plaznik A, Kukwa A, Kostowski $\mathrm{W}$ et al (2006). Nicotine-induced conditioned taste aversion in the rat: effects of ethanol. Eur J Pharmacol 537: 99-105.

Laviolette SR, Alexson TO, van der Kooy D (2002). Lesions of the tegmental pedunculopontine nucleus block the rewarding effects and reveal the aversive effects of nicotine in the ventral tegmental area. J Neurosci 22: 8653-8660.

Le Foll B, Goldberg SR (2006). Nicotine as a typical drug of abuse in experimental animals and humans. Psychopharmacology (Berl) 184: 367-381.

Le Foll B, Goldberg SR (2009). Effects of nicotine in experimental animals and humans: an update on addictive properties. Handb Exp Pharmacol 192: 335-367.

Le Foll B, Wertheim C, Goldberg SR (2007). High reinforcing efficacy of nicotine in non-human primates. PLoS One 2: e230.

Maldonado AM, Finkbeiner LM, Kirstein CL (2008). Social interaction and partner familiarity differentially alter voluntary ethanol intake in adolescent male and female rats. Alcohol 42: 641-648.

Melis MR, Argiolas A (2011). Central control of penile erection: a re-visitation of the role of oxytocin and its interaction with dopamine and glutamic acid in male rats. Neurosci Biobehav Rev 35: 939-955.

Munger SD, Leinders-Zufall T, McDougall LM, Cockerham RE, Schmid A, Wandernoth P et al (2010). An olfactory subsystem that detects carbon disulfide and mediates food-related social learning. Curr Biol 20: 1438-1444.

Palmatier MI, Matteson GL, Black JJ, Liu X, Caggiula AR, Craven L et al (2007). The reinforcement enhancing effects of nicotine depend on the incentive value of non-drug reinforcers and increase with repeated drug injections. Drug Alcohol Depend 89: 52-59.

Perkins KA, Gerlach D, Vender J, Grobe J, Meeker J, Hutchison S (2001). Sex differences in the subjective and reinforcing effects of visual and olfactory cigarette smoke stimuli. Nicotine Tob Res 3: 141-150.

Pletcher MJ, Hulley BJ, Houston T, Kiefe CI, Benowitz N, Sidney S (2006). Menthol cigarettes, smoking cessation, atherosclerosis, and pulmonary function: the Coronary Artery Risk Development in Young Adults (CARDIA) Study. Arch Intern Med 166: 1915-1922.

Rinker JA, Busse GD, Riley AL (2008). An assessment of sex differences in nicotine-induced conditioned taste aversions. Pharmacol Biochem Behav 88: 427-431.

Ross HE, Young LJ (2009). Oxytocin and the neural mechanisms regulating social cognition and affiliative behavior. Front Neuroendocrinol 30: 534-547.

Sargent JD (2005). Smoking in movies: impact on adolescent smoking. Adolesc Med Clin 16: 345-370, ix.

Shram MJ, Funk D, Li Z, Le AD (2006). Periadolescent and adult rats respond differently in tests measuring the rewarding and aversive effects of nicotine. Psychopharmacology (Berl) 186: 201-208.

Shram MJ, Funk D, Li Z, Le AD (2008). Nicotine self-administration, extinction responding and reinstatement in adolescent and adult male rats: evidence against a biological vulnerability to nicotine addiction during adolescence. Neuropsychopharmacology 33: 739-748.

Smith JC, Williams DP, Jue SH (1976). Rapid oral mixing of glucose and saccharin by rats. Science 191: 304-305.

Solomon NG, Yeager CS, Beeler LA (2002). Social transmission and memory of food preferences in pine voles (Microtus pinetorum). I Comp Psychol 116: 35-38.

Stolerman IP, Jarvis MJ (1995). The scientific case that nicotine is addictive. Psychopharmacology (Berl) 117: 2-10; discussion 14-20.

Thiel KJ, Sanabria F, Neisewander JL (2009). Synergistic interaction between nicotine and social rewards in adolescent male rats. Psychopharmacology (Berl) 204: 391-402.

Walker D, Mahoney C, Ilivitsky V, Knott VJ (2001). Effects of haloperidol pretreatment on the smoking-induced EEG/mood activation response profile. Neuropsychobiology 43: 102-112.

Wheeler RA, Twining RC, Jones JL, Slater JM, Grigson PS, Carelli RM (2008). Behavioral and electrophysiological indices of negative affect predict cocaine self-administration. Neuron 57: 774-785.

Wilmouth CE, Spear LP (2004). Adolescent and adult rats' aversion to flavors previously paired with nicotine. Ann NY Acad Sci 1021: 462-464.

Wise RA, Yokel RA, DeWit H (1976). Both positive reinforcement and conditioned aversion from amphetamine and from apomorphine in rats. Science 191: 1273-1275.

Wrenn CC (2004). Social transmission of food preference in mice. Curr Protoc Neurosci Chapter 8: Unit 8 5G. 1-7. 